\title{
Huge Dam and Power Construction Projects A Threat to Natural Environment, Alternatives-The Role of Human Resource Development (HRD)
}

\author{
Kavuluru Venugopal, Abhilasha Ambatipudi
}

\begin{abstract}
The contribution of HRD to any industry for its growth and success cannot be overstated and hence same is the case with construction sector. Simultaneously the role of HRD in regulating pollutants of huge construction projects impacting environment and biodiversity is laudable. If advices and services of HRD are rightly adopted the negative impact on the same can be minimized. In this paper it is emphasized for setting up of alternatives to huge and mammoth construction projects as well as dam hydropower projects for green. Therefore, river environment can be saved for future generations. The involvement of HRD in this area is inseparable. Thus, it has been suggested to policy makers and concerned governments to go for environment friendly designs with the help of HRD for alignment of various departments and better implementation.

Index terms: HRD, environment, construction projects, alternatives.
\end{abstract}

\section{INTRODUCTION}

With growing population, their needs and industrial growth result in new huge construction projects like dams and power generation projects to come up.

Earth is getting warmer due to human activity that plays a vital role in accelerating this process. Construction workings radically have changed the land surface as greater part of the terrain has been cleared off vegetation and excavation. This is a general phenomenon for construction and power projects consequently polluting surrounding water pools with construction wastes. Huge projects generally involve in wide-ranging land disturbance, sometimes tremors in the earth are probable, concerning elimination of vegetation along with reshaping the landscape; such actions make the soil susceptible to erode. Soil separated as a result of erosion can be carried by the wind and generate dust problem otherwise contaminate natural water bodies by being mixed in it. In addition, build materials like concrete, cement and steel are straightly responsible for emitting great extent of carbon dioxide (CO2). Deforestation because of construction can have a negative impact on the environment. The most striking impact is a loss of habitat for millions of species. Hence, deforestation as well

Revised Manuscript Received on July 22, 2019

Kavuluru Venugopal, Research Scholar, KLU Business School, Koneru v.kavuluri2003@gmail.com

Abhilasha Ambatipudi, Associate Professor, KLU Business School, KLEF, Vaddeswaram, Guntur. E-mail: abhilash@kluniversity.in Lakshmaiah Education Foundation, Vaddeswaram, Guntur, A.P,India. E.mail:

compels climate change and biodiversity.

\section{Central upshots as under}

Material: Construction projects always consume significant quantities of steel, copper, aluminum, polymers and plaster of Paris. These materials are excavated from earth crust destructing habitat.

Systemic Impacts: Basically the construction process contributes to the continued operations of systems that cause environmental damage certainly.

\section{OBJECTIVES}

1. To establish that HRD has a vital role to play in regulating huge construction projects for green nature.

2. To oversee alternatives for huge construction and hydropower dams for green.

\section{METHODOLOGY}

This paper is based on a wide assortment of literature review study and on web-based research material. A view of HRD interventions is applied to construction sector to deal with ecological balance and possible end result.

\section{DISCUSSION}

Development of a nation does not mean mere economic development; economic development should be in tune with environmental consciousness. Most of the said to be developed nations are growing economically but degenerating ecologically. Their natural environment cycle is getting flawed. The root cause of this is recklessness towards nature. Therefore it is the responsibility of governments; their departments to be equipped with human resources development (HRD) which enlightens and establishes needed communication net work among the systems for a better cause of understanding nature. Hence, environment friendly projects can come out.

Role of HRD: HRD refers that an organization's focal point must be to enhancing the knowledge base and related skills of the work-force. This is the combined effort of training and career development to better a team or an individual. The role of human resource development is unforgettable in attaining

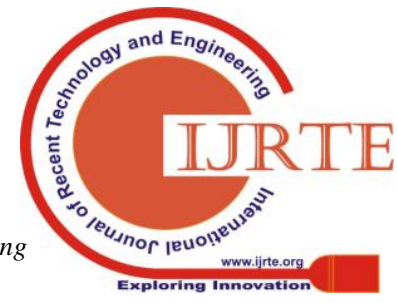


organizational effectiveness. Its practices of personnel appraisal, counseling, reward system for the eminence of work-life are remarkable.

HRD is a novel and forward-looking approach to deal with concerns, allied to an individual employee and a team, along with organizations. And it is a movement to build up organizational potential to supervise a change and challenge. Human Resource Development is a practice of developing skills, competency, know-how, and attitudes of community in any organization. The people develop into human resource only after they become proficient enough to carry out organizational actions. Hence, HRD shall make sure that the organizations have such capable and proficient human resource to accomplish its preferred objectives. This is a usual elucidation, but from standing perspective the responsibilities of HRD are boundary less, exhaustive and all-encompassing.HRD becomes a springboard to bring necessitated departments together to achieve any goal for environmental sustainability. HRD is a system of initiation.

In the early Indian literature, HRD is for all round development of traits - physical, spiritual, ethical as well as environmental; weighing scale between nature and human activities. Living close to nature is its concept. In the western world, prominence is placed on false inducement encompassing of various encouragements. In the Indian background, importance is laid on fine qualities between Human Beings. According to Dr. K.M. Munshi, mere conveying of information is not HRD however it is the building of eminence. The Indian notion of HRD involves in realization of perfection and ethical values, not on earning profits. As a consequence, the scope of HRD in the Indian contemplation is more broad-based and qualitative. According to Swami Chinmayanand ${ }^{1}$, once an indomitable nation ornately plans for its own progress, apart from its political tactics, and economic proposal, it has to look into its own cultural brilliance in order to impart, mould and polish the character of the individuals. The nation - building work commences with the findings of an intellectual composure and a physical dynamism in the youthful and intelligent realm. Hence, it can be learned that nation building is achieved not through economics alone but at its best with environmentalism too. Both are mutual, reciprocal and interdependent magnitudes. Here HRD's role is exclusive and most sought in enlightening governments and people that environment is the function of huge construction and power projects that are from design to finish.

Negative Impacts of Dams: By means of design, dams change the natural flow system, and with this nearly every phase of a river ecosystem, together with water feature, remains transport and deposition, fish migrations and reproduction, riparian and floodplain along with surroundings the organisms that rely on the habitation

Some of the harms with Dams: Biological disturbance,

\footnotetext{
${ }^{1}$ Swami Chinmayanand, "The Art of Man-making" Central chinmaya Trust, June 2002 pp -3
}

movement of fish, residue, plants, and nutrients get affected. Leaching and evaporation of waters are being detained by dams. People along with wildlife that live in the area shall surely be displaced and flooded by dams. Likely dislocation of many people survives downstream of the dam relying on the waters shall be the consequence. In case the dam happened to be breached it would lead to flooding as a result loss of life. Moreover, changes occur to the water table.

Besides the above, construction and operation of especially huge Projects may have negative influence on environment.

Soil dust and stink trouble, quality of water influences due to sudden release of unprocessed dirt or release of treated leakage at the time of maintenance. Solid waste management difficulty connected to the construction as well as demolition materials, and the generation of extra mud. Noise impact shall be there because of the construction and operation works. Gas generated hazards from landfills are also become responsible.

Let certain details of Polavaram project, Andhra Pradesh be examined: As per the Polavaram Project Environmental Impact Assessment (EIA) Report in 1985, projected about 150,700 people were to be moved from approximately 225 villages. For all these years population has grown-up significantly and the tribal population has been observed to be known to grow up above the average. With approximately $8 \%$ growth rate per decade the population will by now be predicted as around 174,000. Nevertheless the data enclosed in administrative summary of EIA report does not tally with 2001 census facts and is distant from actuality. Its design is said to be outdated, unsafe and cannot entirely be considered that the damage expected to be happened to the ecosystem, wild life and habitat for human beings along with diverse transformations that must have got occurred in the social order over the time.

\section{ALTERNATIVE TO DAMS AND POWER PROJECTS}

Dams shall never be the best means to meet the growing demand for irrigation and the rest. They happen to be a lot expensive affair for states. Moreover, citizens and intellectuals should stop bad dam construction that is thoughtless and environmentally hazardous proposal. Sufficient number of check dams can come to rescue of irrigation in result environmental problems can be mitigated.

India stands third in line after America and China in building larger dams. India has above 5,000 big dams. Notwithstanding that, India's water storage is 225 cubic meters in per capita terms stands less against China's which calculates at 1,200 cubic meters stated by T G Sitharam, professor of IIS, Bengaluru. ${ }^{2}$

Environmental flows are portrayed as the quantitative, qualitative and timing of water flows; necessary supporting freshwater and estuarine ecosystems. Dams that intrude with the uninterrupted flow, not only just lead to depression of ground water table in the downstream but also restrict movement of organisms, nutrients and sand along the length of a river that has significant 
effect on downstream aquatic system as well as bio-diversity.

Alternatives to hydropower dams and thermal power stations do exist; providing water and energy services at the same time allow rivers to gush liberally and let the environment be preserved for following generations. Technologies affirm that there are alternatives which may cost lesser than that of hydropower and similarly competent in supplying electricity for domestic-front at rural, urban and industrial purposes.

\section{For example}

1)" Biomass gasfiers, these will burn wastes like rice or corn husks from agricultural produce to generate electricity.

2) Small-scale micro- $(<100 \mathrm{kw})$ and Pico-hydro $(<5 \mathrm{kw})$, these can be run on natural water flows for power generation.

3) Solar and wind generation",3

In addition small water turbines to generate electricity in small scale without depending on major dams. For alternative technologies it is needed to concentrate further on planning and less on new infrastructure besides saving natural resources and protecting environment from constructing huge projects.

\section{Reuse and Ground Water Recharge:}

Water recycle or retrieval, reclaim refers to the utilization of treated sewage, gray water or storm water for non-drinking reasons such as irrigation, industrial processes, fire protection and toilet flushing and the like. This engages recharging underground water or water harvesting that can increase ground water flow during a wet season.

Research Gap: Having been examined allied available reviews that no scientific investigation speaks; HRD can become a prime factor impacting in designing huge construction projects as well as planning. Therefore, in this paper, an attempt has been made to establish that HRD can influence planners and governments to work towards environmentalism in regulating huge construction projects.

\section{RELATED WORK}

The importance of HRD in the past and present and its existence in the period of Vedas are explored [1]. How dams shall negatively impact environment and emphasized the measures to be taken to minimize ecological damage are thoroughly examined here [2], adopting management practices for mitigating environmental impacts produced during construction are perfectly investigated in this [3], sustainability in construction practices have been emphasized and this only can minimize pollutants during construction phase; effective green practices in the sector are essential [4].The problem with dams to ecology and saving environment; it emphasizes on Turbines and Free Flow Kinetic Hydropower Systems on an alternative source are completely addressed [5]. With design dams modify the natural water flows of a river's ecological unit, water eminence; residue transportation with habitat have been dealt thoroughly here [6]. It has been emphasized here that the vigorous resource of any unit becomes the human resource. For implementing any practice and its success depends on a sound HRD [7]. The impacts of construction projects on atmosphere as well as how builders, constructers and units can effort to lessen that influence are examined [8].The very importance and need of a sound human resource management policy against the problems being faced by construction projects in Malaysia. Besides, emphasize has been given on the investigation done and found out managerial role is very essential for healthy communication concerning any task in and among teams [9]. Furthermore dams alone cannot solve total irrigation and other water related requirements; therefore other alternatives should be looked in to, which should be environment friendly [10]. Scrupulously the negative impacts on ecology, wild life and human habitation and on Environmental Public Hearing have been investigated [11]. Report reveals the impact of various HRD training programs that are being taken up to better construction quality in Bhutan [12].

\section{CONCLUSION}

As has been observed, construction of huge projects and hydropower dams have a negative influence on environment and hydrology; affecting rivers' natural flow of waters and biodiversity. Therefore, in this context having emphasized the role of HRD in enlightening planners and governments, the cons of the huge projects are discussed for achieving sustainable environment. And hence HRD becomes crucial for bringing constructive change aligning various departments.

\section{ACKNOWLEDGEMENT}

Author is very grateful to Ch.Krishnamurthy Ms. Swathipundari \& K.Venkatseshu for encouragement and support.

\section{REFERENCES}

[1] Evolution of HRD: by Fredrick H. Harbison, Human Resources as the wealth of nations (New York Oxford University Press, 1973) p3

[2]. Environmental Impacts in the Construction of Dams: by subhojit paul, H.Bhasker singh, Raj deep Habarika- B.Tech in civil engineering, Godavari Institute of Engineering and Technology. AP India (www.ijrd.com volume 2 issue 11 Nov 2013 ISSN: 2278-0211)

[3] Adoption of Environmental Practices on Construction Sites. De Montfort University Leicester-UK by Natasha IIse Rothbucher Thomas Costa-Depatment of Construction University Federal Bahia-Salador-BA-Brazil (online article)

[4] Construction and Environment by Eng. Rehan Ahmed, Head, waste disposable unit, Environmental control Directorate, Public Commission for the Protection of Marine Resources; Environment and Wildlife, Kingdom of Bahrain.

[5] Alternatives to Dams: The Free Flow Kinetic Hydropower Systems: source online, Hydrate life-May 15 2012, by Lynn Henning.

[6] Beyond Dams: Options and Alternatives: A Report by American Rivers, International Rivers Network; by Elizibeth Brink of International Rivers Network and Serena Mc Clain and Steve Rothert of American Rivers Date May 1 2004. www.americanrivers.org and www.irn.org

[7] Human Resource Development (Text and Cases) by Dr Ram Kumar Balyan and Suman Balyan. Himalaya Publishing House, India

[8] The Environmental Impacts of Construction Projects and the Next Steps Forward for the Industry - web source article; e sub - construction software; ported on January 13, 2017 by Tayler.

[9] HRM in the Construction of a Sustainable Development Projects: towards successful completion by I Othman; A. Idrus and M.Napiah, 
Department of civil engineering, Universiti Teknologi Petronas Perak, Malaysia. WIT Transactions on Ecology and The Environment volume.162, copyright 2012 WIT press. Www.witpress.com. ISSN 1743-3541 (online) doi.10.2495/EID 120161.

[10] There are Alternatives to Dams; but we are not talking about them: experts by Subhojit Goswami - Down to Earth-online article December 07.2017.

[11] Mockery of Environment Public Hearing of Polavaram Project in Andhra Pradesh-a web based article, Prepared by Anti-Palavaram Joint Front.

[12] Report on National HRD Needs of the Kingdom of Bhutan, (HRD in Construction sector, seventh chapter) By The Royal Government of Bhutan, November 2010 